\title{
APRESENTAÇÃO \\ MARIA CANDIDA BORDENAVE \\ E A TRADUÇÃO NO BRASIL
}

A tradução no Brasil e Maria Candida Bordenave são dois sintagmas que se interrelacionam. Dentre os principais laços que os unem - para além do 30 de setembro, dia dos tradutores e aniversário de nossa homenageada - estão, entre outros tantos feitos, a estruturação do primeiro Bacharelado em Tradução e Interpretação do país, em fins da década de 1960; a realização dos dois primeiros Encontros Nacionais de Tradutores, em 1975 e em 1985; a coordenação do GT de Tradução da ANPOLL tão logo ele foi criado, em 1987; e a abertura do curso de Especialização em Tradução da PUC-Rio, em 1997. Não faltam motivos, portanto, para justificar a homenagem que esta revista brasileira especializada no campo da tradução vem prestar a Maria Candida Rocha Diaz Bordenave, pioneira no ensino da atividade tradutória em nosso país.

Como seus admiradores e colegas, e editores desta Tradução em Revista, nos reunimos para organizar o presente número, "Homenagem a Maria Candida Bordenave", ao qual damos início com esta apresentação, escrita a seis mãos. Para além de apresentar o volume, lançado neste verão de 2012-2013, pretendemos aqui registrar um percurso da professora Candida.

Como de costume, começamos esta história no ano de 1968, quando da promulgação da nova lei de diretrizes e bases (LDB) que abria aos Departamentos de Letras das universidades nacionais a possibilidade de não mais se restringirem às licenciaturas, criando habilitações em revisão, tradução e interpretação, bem como em crítica literária e em secretariado executivo. Amélia Lacombe, diretora do departamento à época, liderou, juntamente com outros professores, a iniciativa que redundou, em 1969, no oferecimento do bacharelado que visava à formação conjunta de tradutores e intérpretes. Foi então contratada a professora Maria Candida Bordenave, não só tradutora como também intérprete de conferência formada pela Georgetown University, em Washington, D.C. Em 1971 ela começa a ministrar disciplinas do curso por cuja estruturação havia sido responsável. Poucos anos depois, em 1974, é aprovada em concurso público e nomeada Tradutora Juramentada e Intérprete Comercial para a cidade do Rio de Janeiro. Em 1976, forma-se mestre com a dissertação "Contribuições 
FROTA, BRITTO \& MARTINS - Apresentação

da linguística para o ensino da tradução”, cujos capítulos inicial e final integram a Seção II do presente volume.

Duas de nós integramos as turmas de 1970 e de 1971, o que nos permite lembrar o desenvolvimento do curso ao longo do tempo, seus inúmeros ajustes a melhores resultados acadêmicos e a novas tecnologias e rumos no mercado de trabalho. Naqueles anos iniciais do bacharelado, diríamos que a transformação mais radical, já em 19731974, consistiu na separação das habilitações de tradutor e de intérprete, tão logo percebido o hiato nada estreito entre ambas, a primeira realizada exclusivamente no universo da escrita e da leitura (o que mais recentemente deixou de ser verdadeiro), ao passo que a segunda, atividade oral, exigia uma série de técnicas bem específicas relacionadas a voz, atenção, concentração etc. Ficava assim inviabilizada a proposta de reuni-las em um mesmo currículo, o qual já compreendia, como até hoje se dá, todo um conjunto de disciplinas de línguas, literaturas e linguística. Lembramos que a compreensão acerca dessa discriminação curricular valeu, para nós, como um importante ensinamento no que tange às duas atividades.

À frente dessa e das demais mudanças curriculares (das quais passamos a participar em diferentes momentos da história deste Bacharelado em Tradução) estava a professora Candida, sempre cheia de confiança e entusiasmo. Um ponto alto do curso por ela estabelecido, e até hoje preservado, são os Estágios Supervisionados de Tradução, feitos pelos alunos no último ano de sua formação. Dependendo de nossas preferências e aptidões, éramos encaminhados a editoras nacionais como a José Olympio, a Nova Fronteira e a Record, ou a empresas internacionais como a IBM e a Burroughs.

Com sua determinação, Candida não demorava a perceber as demandas e necessidades dos alunos, bem como as viradas que se davam na prática profissional dos tradutores e no campo de seu ensino. Foi assim que, em momentos distintos, as disciplinas de tradução técnica e de tradução literária tiveram o seu oferecimento dobrado e que foram incorporadas as disciplinas de português para tradutores, de terminologia e de teorias de tradução.

Com sua consciência política cada vez mais fortalecida, a professora Candida, com considerável militância dentro e fora da PUC, não tardou em iluminar para seus alunos as determinações e desdobramentos ideológicos das traduções feitas em qualquer tempo e espaço, incluídas aquelas aparentemente destituídas de tais valores. Nessa linha, em associação às políticas terminológicas, ela marcava posição também em 
FROTA, BRITTO \& MARTINS - Apresentação

relação à enxurrada de termos que, vindos dos nossos maiores colonizadores, assimilávamos sem pensar.

Em 1975, a professora Candida movimentou o nosso campus com a realização do I Encontro Nacional de Tradutores, no maior e melhor auditório da universidade, o do Rio Data Centro, cujas poltronas foram insuficientes para receber tantas pessoas, muitas das quais se sentaram nas escadas. Muito articulada e comunicativa, e competente na ampliação dos laços entre o nosso curso de tradutores e a sociedade, Candida, juntamente com o então diretor de Letras Affonso Romano de Sant'Anna - e com o fundamental impulso dado por Paulo Rónai - trouxe para o espaço acadêmico figuras importantes da recém-criada (1974) Associação Brasileira de Tradutores, a ABRATES, que apoiou o evento desde o seu início: dentre outros, Raimundo Magalhães Jr., seu presidente, e Antônio Houaiss, que fez a conferência de abertura. Outros órgãos de classe estavam representados: a Coordenação de Comunicação Social do Estado do Rio de Janeiro, através de seu chefe, o tradutor Otávio Alves Velho; a Associação dos Tradutores Públicos e Intérpretes do Estado da Guanabara (ATPIEG), através de seu então presidente, Giorgio Bullati; e o Ministério da Indústria e Comércio, com a presença de sua tradutora Vilma Vidal. Participaram como conferencistas ou painelistas tradutores que atuavam em diversas editoras, no Instituto Rio Branco, em universidades, cursos particulares de tradução, Cultura Inglesa, Aliança Francesa etc. Até mesmo o ex-governador e tradutor Carlos Lacerda fez uma das conferências.

Dez anos depois, o II Encontro teve êxito equivalente, ficando então estabelecido, pela ali representada classe dos tradutores (cada vez mais consciente de si), que o Encontro Nacional de Tradutores passava à condição de evento bienal itinerante, a ser realizado em diferentes universidades brasileiras.

Publicamos à época os anais desse evento ocorrido em 1985, do qual extraímos duas participações da professora Candida para publicação neste volume. O encontro de 1975, por sua vez, conta com um documento que, além de mostrar o programa, apresenta seus objetivos, conclusões e recomendações. Dado o seu indiscutível valor, não apenas no âmbito das contribuições de nossa homenageada, mas também como testemunho de um dos momentos fundadores da história da atividade tradutória no país, optamos por reproduzi-lo na íntegra aqui neste número de nossa revista.

Também trazemos para este volume um depoimento de Candida que em muitos momentos encontra-se com este nosso relato. Para darmos aqui um gostinho de seu estilo, passemos a palavra à professora: 
Para que vocês conheçam a história do curso, vou ser uma contadora de histórias, ocupação que surgiu ultimamente com grande sucesso. Vou contar a vocês sobre a origem do curso, como foi implantado, as peripécias que enfrentamos, dificuldades e sucessos, voltas e reviravoltas, sempre com muita garra, companheirismo e energia, tendo o maior apoio do departamento. Querem ouvir a história?

Esse depoimento, escrito pela própria protagonista da história, nós conhecíamos apenas na versão de sua apresentação oral, feita em 2007 na abertura da comemoração dos dez anos da Especialização. Aposentada desde 2002, ela fora convidada especial do evento que denominamos "Escola de Tradutores", já que, ao lado daquele aniversário, comemorava-se o centenário de Paulo Rónai, com a participação de Susana Kampff Lages, professora da UFF, e a honrosa presença da viúva de Rónai, Nora.

Nossos leitores podem estar se perguntando por que teríamos mantido a nossa história, já que a outra ("Depoimento de Maria Candida Bordenave - A história do Curso de Tradução da PUC-Rio") está publicada neste mesmo volume. Uma resposta seria a de que toda história não passa de uma estória (razão provável do desaparecimento dessa última, que ela sim merecia ter resistido em detrimento da primeira) e que, portanto, mesmo que se queira atribuir a uma delas, a da protagonistaautora, um peso maior de verdade, uma e outra podem se suplementar, esclarecer, ou mesmo contradizer... Como entendem disso os tradutores!

Retomamos assim a nossa versão, procurando trazer alguns feitos de Candida que não comparecem lá em seu depoimento. Um deles foi a viagem que ela fez em 1982 à Alemanha e à França para conhecer, respectivamente, os cursos de tradução das universidades de Heidelberg e Paris III, mais particularmente a ESIT, École Supérieure d'Interprètes et de Traducteurs. Alguns de nós lembramos os preparativos para a viagem, o levantamento de informações sobre os nossos cursos, e sobretudo sua volta, animada por tantas novidades, materiais impressos e a feliz constatação de que nesta universidade dos trópicos não ficávamos em quase nada a dever. Sem dúvida, uma importante diferença constatada entre os universitários europeus e os brasileiros foi o domínio de três idiomas pelos primeiros, fato entre eles corriqueiro e praticamente inexistente entre nós. Isso trazia, e traz, marcantes diferenças na estruturação dos cursos, que, se lá trabalham com três línguas em diferentes direções, aqui em geral trabalham com o inglês, este quase sempre apenas como língua de partida.

Também nos primeiros anos da década de 1980, com o boom dos cursos de Comunicação e a correlata diminuição da procura pelos cursos de Letras, a professora 
FROTA, BRITTO \& MARTINS - Apresentação

Candida, percebendo uma forte demanda reprimida pela tradução entre pessoas já formadas em outras áreas, cria um curso de formação de tradutores em formato de curso de extensão, com a duração de dois anos. Esses alunos somavam-se aos alunos regulares da graduação, nas turmas de disciplinas específicas de tradução, criando uma nova realidade, bem mais rica e complexa. Esse curso existe até hoje, sendo que nos primeiros anos do novo século ganhou autonomia, separando-se da graduação e sendo deslocado para o campus da PUC que se localiza no centro da cidade. Outro curso criado sob a coordenação de Candida foi o de Especialização em Tradução, que recebeu sua primeira turma em 1997.

Além de sua atuação na docência e na institucionalização da profissão de tradutor, Candida foi também pioneira na área de pesquisa em Estudos da Tradução. No período 1987-1988, ela recebeu bolsa de produtividade do CNPq, embora não tivesse o título de doutora. Esse fato indica como os tempos mudaram: na década de 1980, a área acadêmica tinha uma estruturação bem menos rígida do que hoje em dia. Não eram muitos os acadêmicos de Letras que possuíam doutorado, e aceitavam-se para publicação nos periódicos artigos mais breves, sem um pesado arcabouço de notas e referências bibliográficas. Na área específica de tradução, isso era ainda mais evidente, pois muitos dos melhores tradutores do país não possuíam pós-graduação, nem qualquer inserção acadêmica. Candida tinha uma consciência aguda de como era importante para o tradutor a competência profissional, mesmo que não viesse acompanhada de títulos universitários, o que ficou claro na composição do quadro de professores do curso de especialização, quando ela defendeu com muita garra a especificidade de nossa área, indo contra as exigências formais de um alto percentual de docentes com mestrado e doutorado.

Este número de Tradução em Revista se divide em três partes. Na primeira, reunimos alguns escritos de Candida, artigos e textos de palestras proferidas. A segunda contém um curriculum vitce da homenageada, uma entrevista por ela concedida e diversos documentos produzidos nos diferentes eventos que ela organizou, além de algumas seções da sua dissertação de mestrado. Fechando a publicação, temos um apanhado de depoimentos pessoais, um deles da própria Candida (a já mencionada história do Curso de Tradução da PUC-Rio), e outros de pessoas que colaboraram com ela em diferentes momentos de sua trajetória profissional.

Lembramos a ênfase que, como nossa professora, Candida dava à prática tradutória, sempre reafirmando que "traduzir se aprende traduzindo". Não que 
FROTA, BRITTO \& MARTINS - Apresentação

desvalorizasse trabalhos teóricos, mas porque nos idos dos anos setenta praticamente inexistiam estudos dessa natureza sobre a tradução. Como demonstra sua dissertação, era em geral à linguística que se recorria quando se queria refletir sobre a tradução ou compreendê-la melhor através de recursos conceituais e metalinguísticos. A professora Candida, lembramos, citava amiúde a Roman Jakobson, suas funções da linguagem, sua teoria da comunicação: aos elementos que compunham a rede de comunicação postulada pelo linguista russo (remetente, destinatário, mensagem, contexto etc.) eram aproximadas as figuras do autor, do original, do tradutor, dos leitores...

Como nossa colega, sempre líder, nos lembramos das inúmeras reuniões, de várias viagens, planos e realizações. Como nossa amiga, nos lembramos de sua animação, bom humor e companheirismo.

Esperamos que seu legado possa também inspirar futuros tradutores, professores e estudiosos da tradução, assim como inspiraram a nós e a tantos outros até hoje.

\author{
Maria Paula Frota \\ Paulo Henriques Britto \\ Marcia A. P. Martins
}

Rio de Janeiro, dezembro de 2012 